\title{
Aplicação prática do Postponement em uma empresa têxtil
}

\author{
Mauricio Johnny Loos ${ }^{\text {a* }}$, Carlos Manuel Taboada Rodriguez \\ aniversidade Federal de Santa Catarina, Florianópolis, SC, Brasil \\ *mauricioloos@hotmail.com
}

\section{Resumo}

As organizações buscam, de forma cada vez mais incessante, maneiras atender seus clientes mais rápido que os concorrentes, sendo eficientes e eficazes, não elevando seus custos, e isso exige que elas façam mais com menos, buscando a adoção de técnicas que venham ao encontro de suas estratégias. Nesse contexto, este trabalho objetiva apresentar e analisar a aplicação prática do postponement em uma empresa têxtil. 0 trabalho utiliza o estudo de caso como abordagem metodológica, cujas evidências foram coletadas de diversas fontes. Os resultados mostram um entendimento da estratégia de manufatura usada pela empresa sem e com a adoção do postponement, bem como a visão dos impactos desta aplicação nos indicadores de desempenho da empresa onde ocorreu o estudo.

\section{Palavras-chave}

Postponement. Decoupling point. Empresa têxtil. Indicadores de desempenho. Estratégia de manufatura.

\section{Introdução}

Cada vez mais aumenta a exigência dos clientes em relação aos prazos de entregas, sendo este um dos fatores determinantes, junto com a qualidade e custo, para que as empresas alavanquem seus negócios e convençam seus clientes a colocarem novos pedidos de compra. Diante disso, faz-se necessário as empresas encontrarem formas de reduzir seus lead-times de produção e, consequentemente, seu time-to-market, caso contrário os clientes procurarão outras formas de abastecimento mais convenientes.

Uma das estratégias que ajuda as empresas a conseguirem rápidas respostas para o mercado, bem como redução de custos, se bem aplicada, é o postponement ou adiamento. Nesse contexto, Zinn \& Bowersox (1988) afirmam que o princípio do postponement pode ser estabelecido da seguinte forma: o tempo da remessa e a localização do processamento do produto acabado na distribuição deveriam ser adiados até que os pedidos do cliente fossem recebidos. A ideia que sustenta esse princípio é a de evitar que se remetam mercadorias antes da confirmação da ocorrência da demanda (adiamento) e evitar que o produto acabado tenha sua forma elaborada antes de ser confirmada pelo comprador (adiamento de forma).

Nesse contexto, o objetivo deste trabalho é apresentar e analisar a aplicação prática do postponement em uma empresa têxtil. 0 trabalho pretende responder à questão de quais os impactos da aplicação do postponement nos indicadores de desempenho em empresa da área têxtil, bem como associar as decisões tomadas em relação ao postponement com a literatura. 0 trabalho foi conduzido em uma empresa têxtil, devido à necessidade de se ter um melhor entendimento dos impactos do postponement especificamente na área têxtil, o que se justifica pela carência de trabalhos apresentados sobre postponement neste setor, que está em constante desenvolvimento e responsabiliza-se por grande parcela da movimentação da economia brasileira, com 3,5\% do PIB (Associação Brasileira da Indústria Têxtil e de Confecção, 2011). 0 trabalho adotou como abordagem metodológica o estudo de caso com base na literatura, que compreende um histórico de investigação de um fenômeno, extraído de múltiplas fontes de evidência, de natureza qualitativa ou quantitativa (Barton, 1990). Para a coleta dos dados, foram utilizadas várias fontes de evidência, 
detalhadas mais à frente. Para cumprir seus objetivos, o trabalho primeiramente estabelece o referencial teórico, seguido pelos métodos e técnicas adotados, resultados empíricos e, finalmente, suas conclusões.

\section{Referencial teórico}

A seguir apresenta-se uma fundamentação teórica referente ao postponement, a fim de estabelecer a visão da literatura para, posteriormente, poder-se efetuar as análises de confronto com o trabalho de campo observado na unidade de análise.

\subsection{Conceitos de Postponement}

0 postponement vem sendo discutido há décadas, $\mathrm{e}$ as primeiras experiências práticas utilizando o conceito remontam da década de 1920 . 0 postponement é uma prática que está crescendo e cada vez mais difundida na literatura acadêmica e em aplicações práticas. Inicialmente, o conceito de postponement foi proposto por Alderson (1950), como uma forma de ordenamento de etapas de agregação de valores nos processos de manufatura e de marketing. 0 propósito desta estratégia era reduzir riscos através da manutenção de produtos em uma localização central até o último momento possível, ou em estado indiferenciado até o último ponto possível do fluxo de mercadorias. Assim, postergar a movimentação do produto foi denominado de "postponement de tempo" (time postponement), enquanto a postergação na diferenciação do produto foi denominada de "postponement de forma" (form postponement).

Em 1965, Bucklin agregou mais detalhes ao trabalho de Alderson, estudou limites de aplicação da estratégia e criou o conceito oposto ao de postponement, o Princípio da Especulação (Principle of Speculation). Esse princípio consiste em finalizar todas as operações o mais cedo possível no processo de manufatura (Bucklin, 1965). Os dois princípios são juntamente denominados como princípio de postponement especulação. Esses dois princípios são uma tentativa de explicitar como as partes de um sistema, tais como distribuição e marketing, estão dinamicamente inter-relacionadas. Qualquer alteração em uma parte do sistema propaga-se para as demais. É importante entender que a especulação é o limite do postponement e vice-versa.

Os trabalhos de Alderson e Bucklin sobre postponement foram visionários para seu tempo, porém os longos lead- times na produção e na distribuição tornaram difícil a aplicação do conceito e não despertaram a merecida atenção empresarial na época. Depois de 1965, poucos trabalhos abordaram o assunto, e o tema foi retomado no final da década de 1980 por Zinn e Bowersox.
Para Bowersox \& Closs (1996), existem dois tipos de postponement que são críticos para a formulação da estratégia:

- Postponement de manufatura (forma): objetiva manter os produtos em estado neutro até o último momento possível na cadeia de fornecimento. Estes princípios podem ser aplicados comumente nas indústrias: tintas, petroquímica, automobilística, eletrodomésticos, motociclística, entre outras.

- Postponement da Logística: é exatamente o oposto do conceito de postponement de manufatura, pois consiste em manter toda a linha de produtos, já diferenciada e centralizada. 0 deslocamento dos estoques é adiado até o recebimento dos pedidos dos clientes. Quando a demanda ocorre, os produtos são transportados diretamente ao varejo ou ao consumidor, utilizando meios de transportes.

Os autores Zinn \& Bowersox (1988) ampliaram as alternativas de retardamento, ao proporem também o adiamento de atividades de manufatura (mudança de forma), tais como personalização final e embalagem, principalmente quando os níveis dos erros na previsão da demanda são elevados. Dificuldades na previsão da demanda surgem na medida em que aumenta a incerteza quanto a condições futuras de mercado, e na medida em que são ampliadas as linhas de produtos da empresa. Estes autores identificaram cinco tipos de estratégia de postponement: quatro relacionados com o postponement de forma (etiquetagem, embalagem, montagem e manufatura) e o quinto com a estratégia de postponement de tempo (Zinn \& Bowersox, 1988).

- Postponement de etiquetagem: esta estratégia é eficaz para empresas que comercializam um produto sob duas ou mais marcas. Os produtos são armazenados sem qualquer rótulo ou etiqueta que identifiquem sua marca. Estas só são afixadas mediante a chegada de um pedido de cliente especificando a marca desejada.

- Postponement de embalagem: é viável para produtos vendidos em embalagem de diferentes tamanhos. Segundo o autor, a economia será ainda maior caso seja viável o transporte dos produtos a granel.

- Postponement de montagem: nesse caso, não só a operação de embalagem, mas a atividade de montagem é retardada, até que a empresa receba o pedido do cliente. Isto é possível quando um produto básico é vendido em configurações diferentes, mas semelhantes, que refletem as preferências individuais dos clientes. A possibilidade da aplicação desse tipo de postponement cresce quando a metragem cúbica do produto é significativamente reduzida na operação de transporte. 
- Postponement de fabricação: nesse caso, a fabricação só é concluída após o recebimento de um pedido do cliente. A justificativa econômica fundamental é o transporte e armazenagem de materiais ubíquos (materiais que estão disponíveis em qualquer lugar, o que faz com que apenas quantidades realmente com motivos extremos precisem ser estocadas).

- Postponement de tempo: nesse caso, o fabricante trabalha com estoques centralizados, somente deslocando o produto para o mercado consumidor após o recebimento do pedido do consumidor.

Outra classificação é a de Cooper (1993), que especifica quatro possíveis estruturas para as operações de manufatura, as quais dependem do tipo de operações finais realizadas, do tipo de produto e do mercado. Três características operacionais básicas foram utilizadas para a classificação: marca, formulação e periféricos dos produtos. As quatro estruturas são (Cooper, 1993):

a) Manufatura centralizada (Unicentric postponement) - sistema de manufatura centralizada, em que a fabricação é integrada a uma planta global e a distribuição é feita por encomenda. Adequa-se a casos em que as três características do produto são as mesmas em todos os mercados onde o produto é vendido, ou seja, são padronizados. Assemelha-se ao postponement de tempo.

b) Manufatura agrupada (Bundled manufacturing) ideal para produtos com marca global e formulações diferentes em cada mercado, como aparelhos de TV. Nessa alternativa, a diferenciação do produto é retardada no processo produtivo (na fábrica) e o produto semielaborado é despachado e mantido em localização centralizada (armazém ou centro de distribuição). Essa estratégia é a combinação do postponement de forma com o de tempo.

c) Montagem postergada (Deferred Assembly) sistema de montagem adiada, em que a produção é puxada e a manufatura final dos produtos acontece nos centros de distribuição locais. Adequado para produtos com uma marca global, mas com periféricos diferenciados e formulações diferenciadas. Assemelha-se ao postponement de montagem e fabricação, descritos anteriormente.

d) Embalagem postergada (Deferred Packaging) ideal para quando rótulo e/ou embalagem são diferenciados conforme o mercado. Relaciona-se ao postponement de etiquetagem e embalagem de Zinn \& Bowersox (1988).

Conforme Jones \& Towill (1999), o conceito de postponement tem sido utilizado, efetivamente, por cadeias de abastecimento, como forma de limitar o efeito debilitante da dinâmica do sistema inerente à sua capacidade de atender às demandas dos clientes. 0 adiamento da diferenciação variante de um produto até o último momento possível reduz o risco e a incerteza imposta pelas exigências do consumidor.

Dentre os benefícios do postponement, destacam-se as necessidades reduzidas para estoque, responsividade aumentada pela redução do tempo de ciclo, pela customização e complexidade reduzida nas operações (Appelqvist \& Gubi, 2005).

Muitos dos problemas expostos no fluxo de material são resultados da distorção de informações de demandas do mercado transferidas a montante através da cadeia de suprimentos (Jones \& Towill, 1999). Zinn \& Bowersox (1988) mostram que o postponement é uma eficaz estratégia para aprimorar os sistemas de marketing e distribuição sempre que o nível dos erros na previsão da demanda é elevado.

São várias as formas de classificações relacionadas ao postponement, e Ferreira et al. (2011) apresentam uma sintese delas, conforme Tabela 1.

0 adiamento é favorecido quando as seguintes características se fazem presentes (Zinn \& Bowersox, 1988):

Características tecnológicas e de processamento: viável para desacoplar operações primárias e de adiamento; complexidade limitada de personalização; desenho de produto modular; abastecimento a partir de múltiplas fontes.

Características do produto: alta simplicidade dos módulos; formulação específica dos produtos; periféricos específicos; alta densidade de valor dos produtos; aumento de cubagem e/ou peso do produto mediante a personalização.

Um fator muito importante a ser considerado na estratégia do postponementé o ponto de desacoplamento (decoupling point), que é descrito adiante.

\subsection{Conceitos de decoupling point}

A estratégia de postponement exige muito pensamento cuidadoso quanto à colocação do material no ponto de desacoplamento (decoupling point). Isso basicamente cria um estoque estratégico, que atua como um buffer planejado entre cada um dos lados da cadeia de abastecimento (Jones \& Towill, 1999).

0 ponto de desacoplamento é um termo-padrão para a posição do material onde o fluxo de produto muda de "empurrado" para "puxado". 0 ponto de desacoplamento é formalmente definido como (Hoekstra \& Romme, 1992): o ponto no eixo produto a que o pedido do cliente penetra. É onde as atividades do pedido dirigido e a previsão se encontram. Como regra, o ponto de desacoplamento coincide com um ponto de estoque importante, a partir do qual o cliente tem de ser abastecido. 
Tabela 1. Síntese das classificações de postponement.

\begin{tabular}{|c|c|}
\hline Autor & Classificações de Postponement \\
\hline Alderson (1950) & $\begin{array}{l}\text { Postponement de forma } \\
\text { Postponement de tempo }\end{array}$ \\
\hline Zinn \& Bowersox (1988) & $\begin{array}{l}\text { Postponement de forma é subdividido em } 4 \text { tipos: } \\
\text { - de etiquetagem } \\
\text { - de embalagem } \\
\text { - de montagem } \\
\text { - de fabricação } \\
\text { Postponement de tempo }\end{array}$ \\
\hline Bowersox \& Closs (1996) & $\begin{array}{l}\text { Postponement de manufatura (= de forma) } \\
\text { Postponement logístico (= de tempo + de lugar) }\end{array}$ \\
\hline Van Hoek (1999) & $\begin{array}{l}\text { Postponement de forma } \\
\text { Postponement de tempo } \\
\text { Postponement de lugar }\end{array}$ \\
\hline Pagh \& Cooper (1998) & $\begin{array}{l}\text { Especulação total } \\
\text { Postponement de manufatura (= de forma) } \\
\text { Postponement de logística (= de tempo + de lugar) } \\
\text { Postponement total }\end{array}$ \\
\hline Waller et al. (2000) & $\begin{array}{l}\text { Postponement upstream } \\
\text { Postponement downstream (= postponement de forma) } \\
\text { Postponement de distribuição (= postponement de lugar) }\end{array}$ \\
\hline Cardoso (2002) & $\begin{array}{l}\text { Ausência de postergação } \\
\text { Centralização de estoques (= de lugar) } \\
\text { Diferenciação do produto (= de forma) } \\
\text { Combinações }\end{array}$ \\
\hline Yang et al. (2004) & $\begin{array}{l}\text { Postponement de projeto do produto } \\
\text { Postponement de compras (= postponement upstream) } \\
\text { Postponement de produção (= de forma) } \\
\text { Postponement logístico (= de tempo + de lugar) }\end{array}$ \\
\hline Garcia-Dastugue \& Lambert (2007) & $\begin{array}{l}\text { Postponement pela mudança na sequência das atividades (= de forma) } \\
\text { Postponement baseado no tempo (= de tempo) }\end{array}$ \\
\hline
\end{tabular}

Fonte: Ferreira et al. (2011).

0 ponto de desacoplamento existe para o fluxo de material e de informação, sendo que este último requer uma definição própria e é definido como: o ponto no canal de informações para que os dados do pedido de vendas processem sem modificação. É aqui que os fluxos da informação de mercado e previsão se encontram (Jones \& Towill, 1999).

A Figura 1 mostra as posições dos pontos de desacoplamento da cadeia de suprimentos e, conforme Rudberg \& Wikner (2004), a posição do ponto de desacoplamento depende do balanço de duas forças contrárias: produtividade e flexibilidade. Quando o custo é a principal vantagem competitiva, produtividade força o ponto de desacoplamento a jusante. Por outro lado, quando flexibilidade e exigências específicas do consumidor são os objetivos, flexibilidade empurra a posição do ponto de desacoplamento a montante.

0 trade off produtividade-flexibilidade e o posicionamento do ponto de desacoplamento é mostrado na Figura 2, e Yang \& Burns (2003) destacam que, como muitos dos produtos hoje oferecem variações, opções e características customizadas, há vários pontos de diferenciação do produto que podem ser determinados por múltiplos atributos do produto, objetivos do segmento de mercado e regiões de venda. Por exemplo, produtos de base geral podem ser primeiro diferenciados em famílias e, mais tarde, em produtos finais individuais. As companhias podem simplesmente manter os produtos em estado não acabado no primeiro ponto de diferenciação do produto até que o pedido do consumidor chegue. Em outras palavras, um pedido do consumidor não tem de ser completamente especificado em um único ponto no tempo. lsso também dá aos consumidores liberdade para especificar certos detalhes do seu pedido e, mais tarde, detalhes adicionais (Yang \& Burns, 2003).

A Figura 3 proposta por Yang \& Burns (2003) exemplifica os vários pontos de desacoplamento possiveis e o seu relacionamento com postponement.

Nota-se na Figura 3 as diferentes estratégias de postponement, variando do postponement puro até a especulação pura. As linhas pontilhadas separam as atividades feitas sob previsão (destacadas na cor branca) e as orientadas pelos pedidos (cor cinza), e representam o ponto de desacoplamento para cada um dos estágios da cadeia de suprimentos. Da esquerda para direita, a profundidade do postponement aumenta e o ponto de desacoplamento se torna mais distante do usuário final. 0 “postponement é usado para mover o 


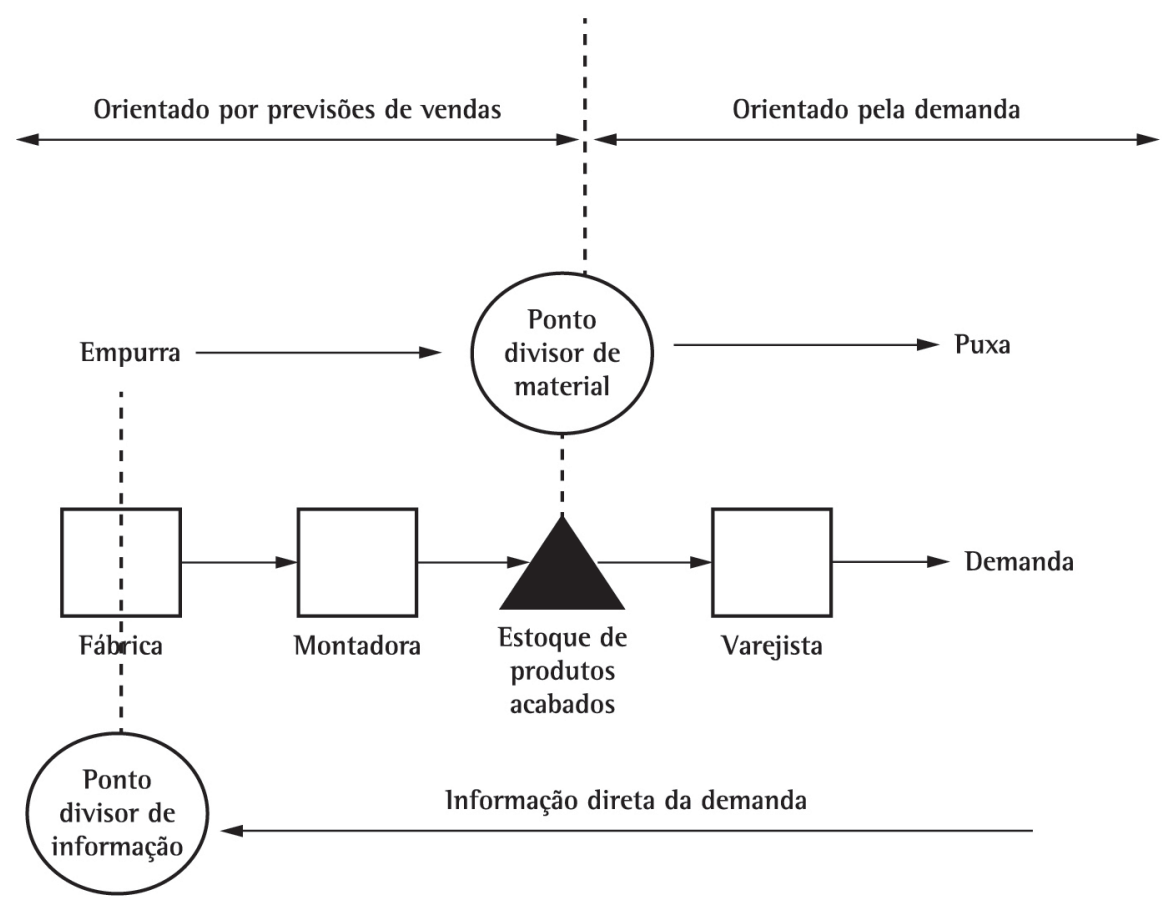

Figura 1. Posições dos pontos de desacoplamento na cadeia de suprimentos. Fonte: Adaptado de Jones \& Towill (1999).

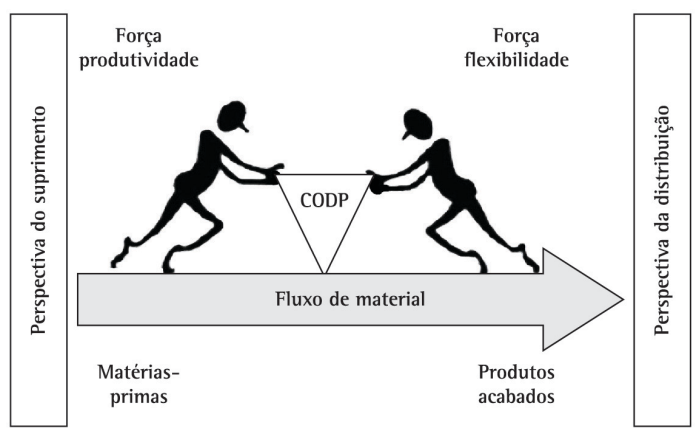

Figura 2. 0 trade off produtividade-flexibilidade e o posicionamento do ponto de desacoplamento. Fonte: Adaptado de Rudberg \& Wikner (2004).

ponto de desacoplamento mais perto do consumidor final e aumentar a eficiência e efetividade da cadeia de suprimentos." (Yang \& Burns, 2003).

\subsection{Postponement e modularidade}

A habilidade de uma empresa utilizar a abordagem do postponement depende em parte do grau de modularidade de seus produtos e processos. No entanto, tais sistemas não são fáceis de serem projetados e operados. Segundo Dornier et al. (2000), a modularidade é um método de projeto do produto em que o produto é montado a partir de um conjunto de unidades constituintes padronizadas. Com isso, diferentes combinações para um dado conjunto de unidades padronizadas dão origem a diferentes modelos e variações de produtos finais.

Dornier et al. (2000) enfatiza que as empresas que melhor implementarem a modularidade e o postponement podem obter vantagem competitiva sustentável ao longo da cadeia de suprimentos. Isso possibilita o fornecimento de produtos customizados sem a perda dos benefícios da economia de escala. 0 verdadeiro desafio da modularidade é projetar mecanismos de montagem eficientes e desenvolver produtos que possam ser separados e ter suas partes padronizadas (Starr, 1965).

Yang et al. (2004) definem duas formas de modularidade:

- A modularidade no projeto -refere-se à definição dos limites do projeto de um produto e de seus componentes, de modo que as características e as tarefas de projeto evitem a criação de fortes interdependências entre componentes específicos (módulos) (Baldwin \& Clark, 1997). Uma arquitetura inteiramente modular significa que uma mudança feita a um componente não exige uma mudança a outros componentes (Ulrich, 1995).

- A modularidade na produção - refere o projeto do processo de produção a fim de fazer produtos complicados, projetando e desenvolvendo os 
módulos em locais diferentes e unindo-os para criar um sistema completo (Baldwin \& Clark, 1997). Esta modularidade divide o processo de produção em subprocessos que podem ser executados simultaneamente ou em uma ordem sequencial diferente (Lee, 1998).

Grande parte dos autores que descrevem sobre o tema modularidade considera que a modularidade (no processo de manufatura) é um facilitador e, em alguns casos, um pré-requisito para o postponement (Lee, 1998; Yang et al., 2004; Van Hoek, 2001).

Segundo lee (1998), para habilitar o atraso de algumas partes dos processos, é necessário que o processo possa ser quebrado em pequenos subprocessos pela modularidade. Adicionalmente, Yang et al. (2004) também afirmam que a modularidade nos processos é um pré-requisito para o postponement.

Van Hoek (2001) também investiga o relacionamento entre postponement e modularidade, e destaca dois impactos da modularidade no postponement. 0 primeiro é que a modularidade habilita a manufatura final rápida a baixo custo de processamento e aumenta a possibilidade de ajustar produtos aos mercados. 0 segundo é que alta comonalidade de peças reduz os níveis de estoque e o risco de estoques obsoletos. Entretanto, a modularidade no processo de produção é necessária para o postponement, e modularidade no produto facilita o postponement por contribuir para o desempenho de custos e reduzir o risco de obsolescência.

\subsection{Estratégias de Postponement e abordagens importantes para sua implementação}

Pagh \& Cooper (1998) combinaram quatro estratégias de postponement para a cadeia de suprimentos em uma matriz, conforme Tabela 2.

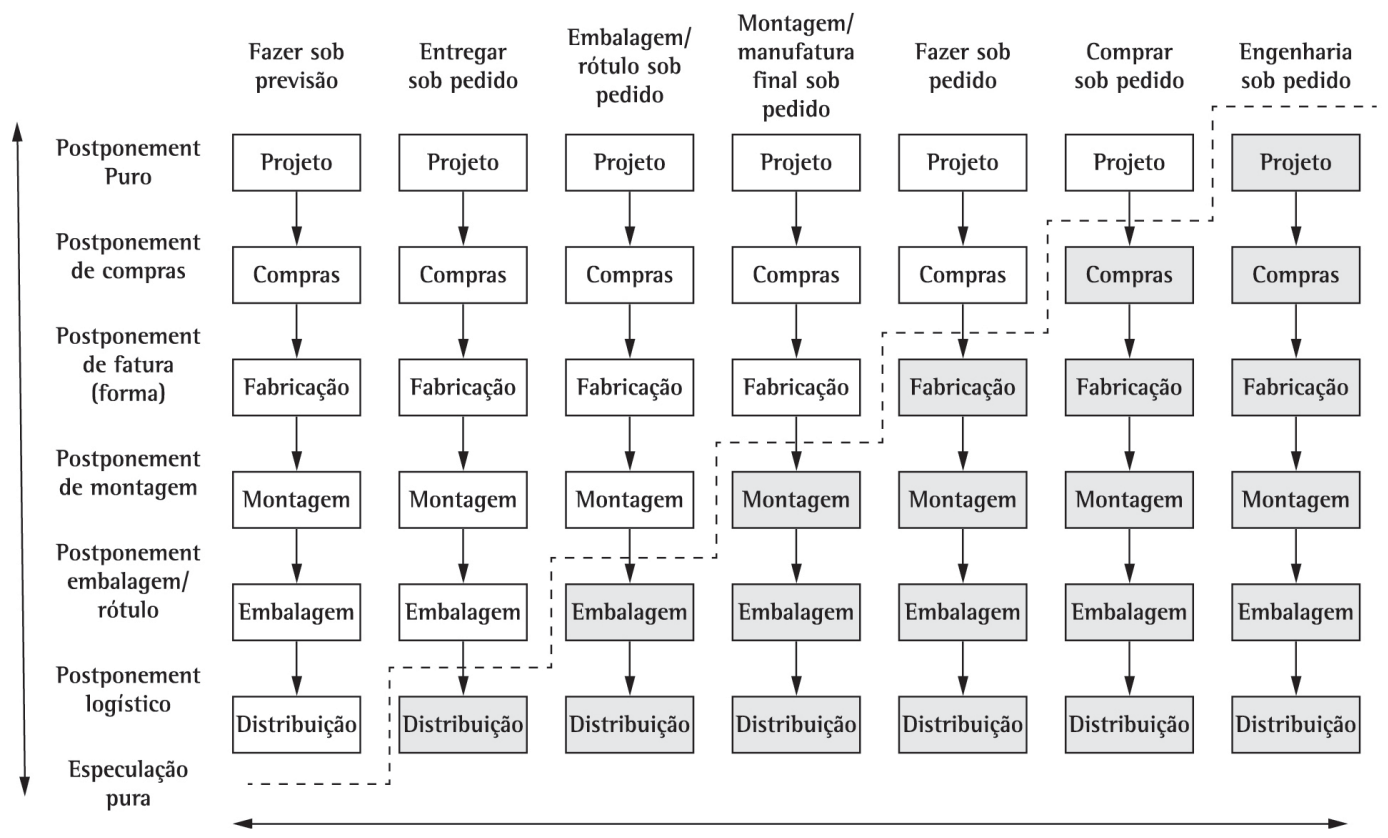

Figura 3. Estratégias de postponement e posicionamento do PD. Fonte: Yang \& Burns (2003).

Tabela 2. Matriz postponement especulação e estratégias genéricas da cadeia de suprimentos.

\begin{tabular}{|c|c|c|c|}
\hline & & \multicolumn{2}{|c|}{ LOGísTICA } \\
\hline & & $\begin{array}{c}\text { Especulação } \\
\text { Estoques descentralizados }\end{array}$ & $\begin{array}{l}\text { Postponement } \\
\text { Estoques centralizados e distribuição direta }\end{array}$ \\
\hline \multirow{2}{*}{ 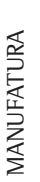 } & $\begin{array}{l}\text { Especulação } \\
\text { Fabricação para } \\
\text { estocagem }\end{array}$ & Estratégia de especulação total & Estratégia de postponement de logística \\
\hline & $\begin{array}{l}\text { Postponement } \\
\text { Fabricação por } \\
\text { pedidos }\end{array}$ & Estratégia de postponement de manufatura & Estratégia de postponement total \\
\hline
\end{tabular}


Na matriz, postponement de forma é chamado de postponement de manufatura (manufacturing postponement), e postponement de tempo é chamado de postponement logístico (logistic postponement). As quatro estratégias são então desenvolvidas pela combinação do postponement de manufatura e logística. As duas primeiras estratégias são representadas tanto pelo postponement de manufatura como pelo postponement logístico. As outras duas são formadas pela combinação de ambas, denominada de estratégia de postponement total, e pela ausência de ambas, denominada de estratégia de especulação completa.

A estratégia de especulação é a mais utilizada no mercado. Todas as operações de manufatura e logística são concretizadas o mais cedo possível, baseadas em previsões de vendas, conforme mostra a Figura 4. Os produtos são posicionados próximos aos consumidores e deslocados através de sistemas de distribuição descentralizados. Como resultado, tem-se inventários descentralizados e elevado investimento em estoques.
$\mathrm{Na}$ estratégia de postponement de manufatura, algumas operações, tais como pequena operação, montagem, embalagem ou fixação de rótulos, são realizadas dentro dos canais de distribuição, depois de realizada a diferenciação logística, conforme mostra a Figura 4. Esta operação é adiada até a consolidação do pedido dos clientes.

$\mathrm{Na}$ estratégia de postponement de logística, o planejamento da produção é especulativo, porém a logística é adiada. Os pedidos dos clientes são atendidos a partir de estoques centralizados, conforme mostra a Figura 4. Esta estratégia reduz os inventários e consequentemente o capital necessário para manter os serviços satisfatórios ao cliente, mas a desvantagem desta abordagem é o aumento das despesas com transporte em decorrência da necessidade de entregas rápidas em pequenas quantidades.

A estratégia de postponement plena representa o maior nível possível de postponement, consiste em somente realizar as operações de manufatura e logística contrapedidos dos clientes, conforme mostra a Figura 4. 0 resultado é o baixo custo com
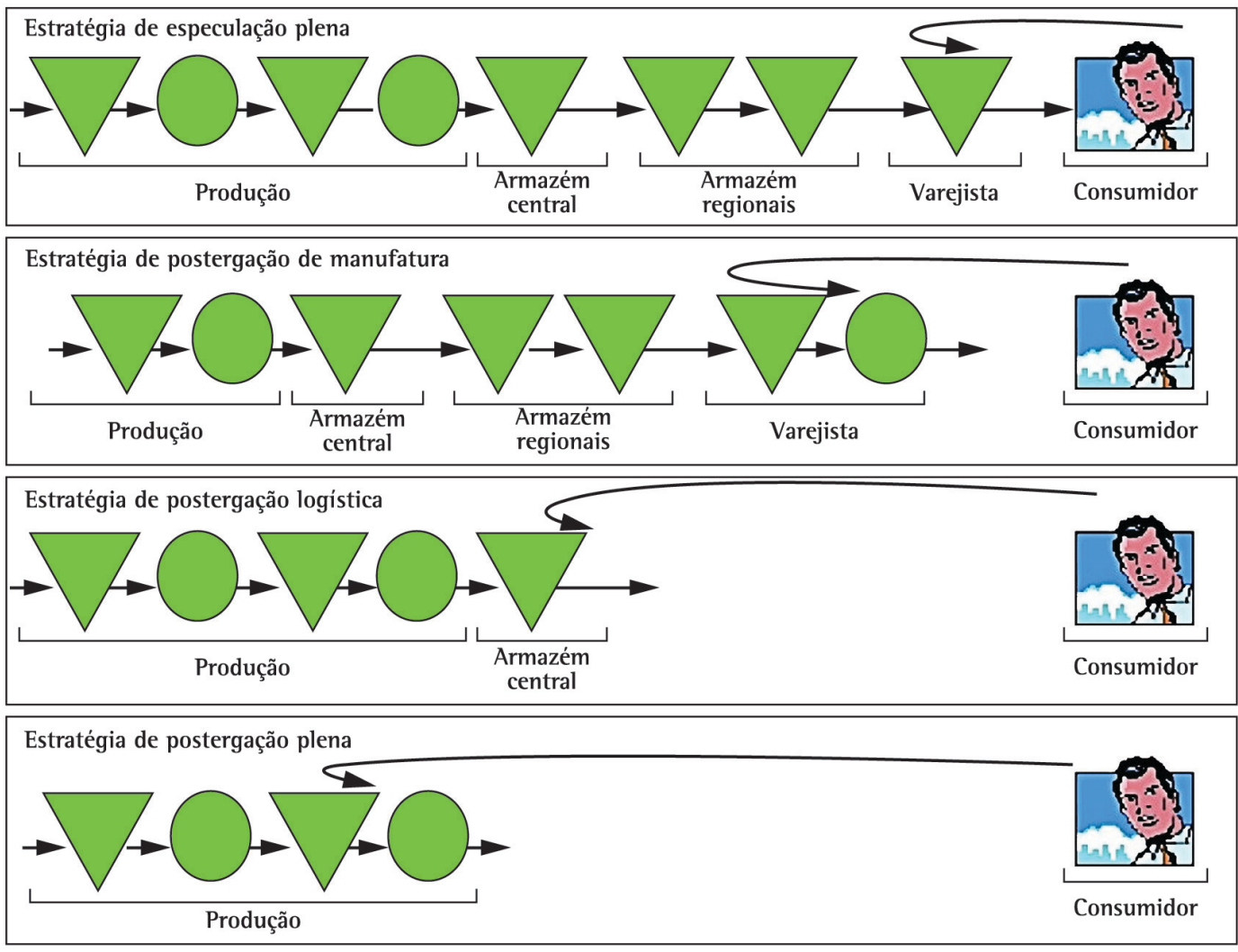

$\square$ Inventário $\quad \begin{aligned} & \text { Fluxo de } \\ & \text { material }\end{aligned} \quad \begin{aligned} & \text { Processo de } \\ & \text { manufatura }\end{aligned} \quad \begin{gathered}\text { Ponto de pedido do } \\ \text { varejista/cliente }\end{gathered}$

Figura 4. Conceituação das diferentes estratégias de postponement. Fonte: Pagh \& Cooper (1998). 
inventários de fabricação e logística, e a desvantagem é a perda das economias de escala.

Em relação à implementação do postponement, Van Hoek (1997) afirma que o importante é adotar o tipo de postponement mais adequado às características de cada empresa, e a Figura 5 mostra o papel da diferenciação do produto na categorização do postponement. Em estudo sobre a aplicação do conceito, o mesmo autor elaborou modelos de decisão que ajudam determinar qual o tipo de postponement deve ser adotado com base nas características do produto, processo, tecnologia e mercado. Esses modelos são baseados nos tipos de postponement propostos por Cooper (1993), e Zinn \& Bowersox (1988), já mencionados.

Outra metodologia para escolha do tipo de postponement é apresentada por Pagh \& Cooper (1998), que desenvolveram o conceito de análise do perfil (Profile Analysis), conforme mostra a Figura 6, que possui as quatro estratégias de postponement como

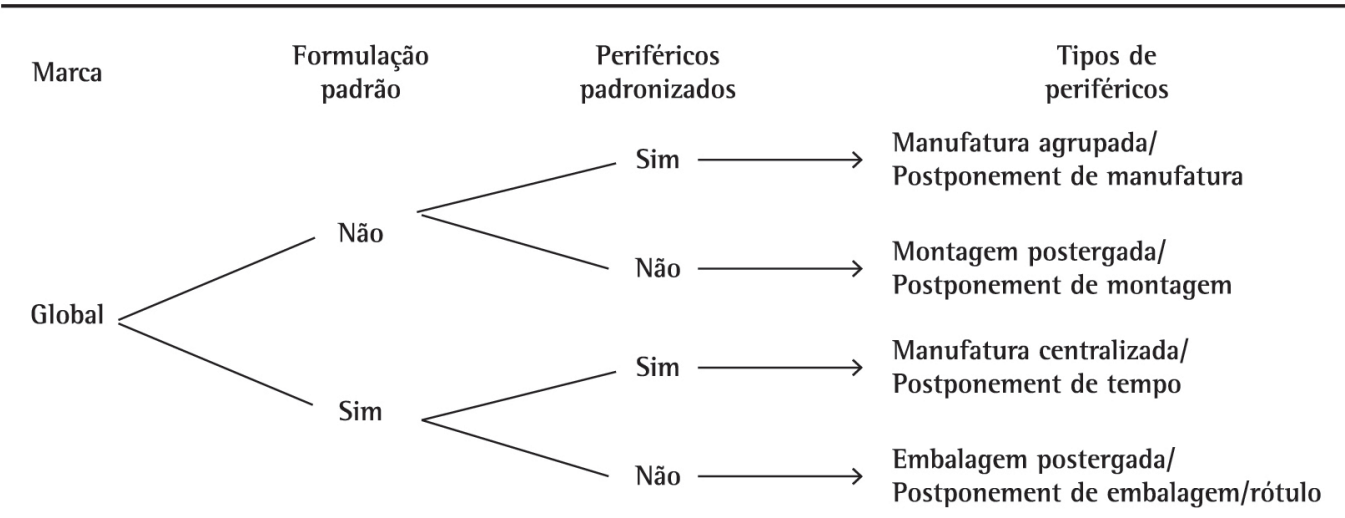

Figura 5. 0 papel da diferenciação do produto na categorização do sistema de postponement. Fonte: Adaptado de Van Hoek (1997).

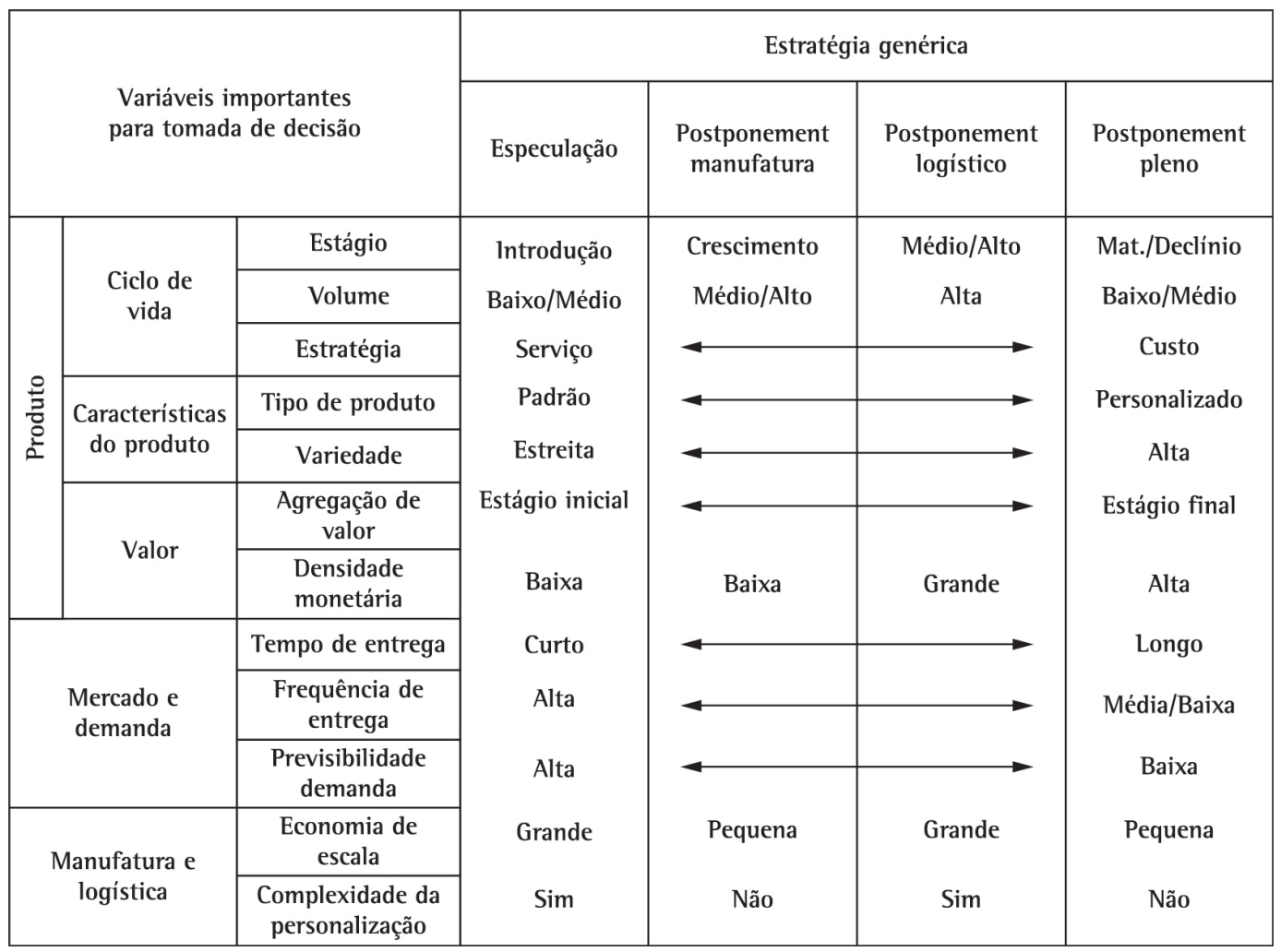

Figura 6. Análise de perfil. Fonte: Adaptado de Pagh \& Cooper (1998). 
colunas e os determinantes como linhas. 0 objetivo da Análise e Perfil é avaliar o alinhamento dos determinantes com uma estratégia de postponement em particular. lsso pode ajudar executivos a avaliar qual seria o projeto de cadeia de suprimento ideal para um determinado segmento de mercado - postponement ou especulação - e também pode ajudá-los a predizer futuras mudanças na estratégia de postponement, quando mudanças nos determinantes forem previstas.

As principais variáveis consideradas neste modelo são: estágio do ciclo de vida do produto, volume, estratégia de custo/serviço, tipo de produto, variedade, perfil de valor, densidade monetária, tempo de entrega, frequência de entrega, nível de instabilidade da demanda, economia de escala e complexidade da personalização (Pagh \& Cooper, 1998).

Como para muitas das implantações, a do postponement também possui alguns obstáculos, que são descritos a seguir.

\subsection{Obstáculos à adoção do postponement}

Bowersox \& Closs (1996) listam algumas barreiras para a efetiva mudança de orientação dos sistemas de distribuição e chamam a atenção para as necessárias mudanças nos papéis tradicionalmente desempenhados pelos canais de distribuição, para acomodar a implementação da estratégia de postponement. Estas barreiras são: a necessidade de as empresas de capital aberto projetarem e informarem lucros trimestrais a analistas e investidores, em razão destas metas incentivarem estratégias promocionais para "saturar os canais de distribuição", de modo a criar volume de vendas fictícias; e maior facilidade de gerenciar com base no poder e relações antagônicas do que desenvolver relações cooperativas.

Na implantação das oportunidades de postponement, algumas questões precisam ser consideradas (Zinn, 1990):

1. É necessário avaliar detalhadamente os custos de postponement versus os custos relativos ao status quo, a prática corrente de se alocar produtos para armazém ou lojas, com base nas previsões de vendas.

2. 0 controle de qualidade precisa ser descentralizado, no caso de transferência de parte do processamento para o nível das lojas e/ou armazéns. A dimensão interorganizacional é importante quando as instalações do varejista não são propriedades do fabricante ou firma distribuidora. A ameaça de adulteração dos produtos pode impedir que as empresas processem seus produtos no varejo, mesmo havendo vantagens de custos.
Para Christopher \& Towill (2000), o maior problema das cadeias de suprimentos é a pouca visibilidade da demanda real de mercado. Na maioria dos casos, grande parte das atividades de fabricação e distribuição é orientada por previsões, e não pela demanda. Existem diferentes situações, podendo variar desde um ambiente de "fabricar por encomenda", na qual a demanda seja inserida até a outra extremidade da cadeia, até a situação comumente encontrada no mercado, em que apenas o último membro da cadeia, aquele em contato com o consumidor, conhece a real demanda do mercado.

Para Christopher (1997), o desafio para a cadeia de fornecimento é encontrar meios de empurrar o ponto de penetração do pedido o mais longe possível da cadeia. Ao mesmo tempo, procurar maior flexibilidade em manufatura e logística pode contribuir para capacidade de manter o estoque em uma forma mais genérica ou inacabada, sendo apenas convertido em sua forma final quando a demanda real for identificada.

\section{Métodos e técnicas de pesquisa}

Primeiramente, cabe destacar que o tema postponementé abordado de forma bastante constante na literatura, tanto teórica quanto empiricamente. No entanto, quando se refere à investigação desse tema especificamente para o setor têxtil no país, não são muitos os trabalhos encontrados no país. 0 presente trabalho tem como propósito abordar o tema postponement do ponto de vista empírico, confrontando os resultados de campo com a teoria vigente. Assim, um de seus propósitos é apresentar e analisar a aplicação prática do postponement em uma empresa têxtil.

Nesse contexto, este trabalho utiliza como abordagem metodológica o estudo de caso, que compreende um histórico de investigação de um fenômeno, extraído de múltiplas fontes de evidência, de natureza qualitativa ou quantitativa, tais como: observação, entrevistas, análise documental, dentre outras (Barton, 1990). A escolha dessa abordagem justifica-se em função de o tema ser contemporâneo e a relevância do contexto de pesquisa (recorte seccional em empresa do segmento têxtil). 0 setor é um dos grandes responsáveis pela movimentação da economia brasileira, com 3,5\% do PIB (Associação Brasileira da Indústria Têxtil e de Confecção, 2011), e cada vez mais vem buscando formas de ser mais ágil, para encarar a concorrência com produtos importados.

A seleção do objeto de análise (empresa) ocorreu devido à necessidade de um melhor entendimento dos impactos do postponement especificamente 
na área têxtil, e nos indicadores de desempenho desta empresa específica. Inicia-se por meio de um diagnóstico da sua estratégia atual de manufatura e a posterior estratégia com a adoção do postponement. A empresa investigada é de grande porte (com cerca de 3.600 funcionários e aproximadamente R\$ 400 milhões de faturamento anual), possui duas unidades industriais, projetando e fabricando produtos têxteis direcionados ao mercado interno (93\%) e externo (7\%). A organização é considerada a segunda maior empresa têxtil do Brasil em cama, mesa e banho, e conta atualmente com grande quantidade e variedade de novos produtos desenvolvidos. Esses aspectos, associados ao acesso facilitado aos dados e informações, em virtude de um dos autores ter participação nas atividades da empresa, justificam a escolha da empresa objeto de análise.

Para a coleta de dados, diversas fontes de evidência foram utilizadas, dentre as quais se destacam: o acompanhamento de reuniões sobre a estratégia de manufatura; discussão da implantação do postponement com as áreas de planejamento e produção; análise documental de planilhas e indicadores de desempenho e entrevistas não estruturadas.

Os dados, predominantemente de caráter qualitativo, foram interpretados utilizando as diversas fontes de evidência, buscando divergência e convergência, confrontando a teoria vigente com as informações práticas coletadas na empresa, através dos quais o caso foi construído.

\section{Resultados empíricos}

A seguir apresentam-se os resultados empíricos do estudo de caso, que mostram como se deu a implantação do postponement na estratégia de manufatura da empresa têxtil pesquisada, bem como os impactos em seus indicadores de desempenho.

\subsection{Caracterização do fluxo produtivo da empresa têxtil pesquisada}

Para conseguir entender como a implantação do postponement ocorreu na empresa pesquisada, é importante entender o macrofluxo produtivo da empresa, apresentado na Figura 7.

0 processo produtivo da empresa se inicia na área de fiação, que é responsável por transformar fibras de algodão e poliéster em fios. Após o processo de fiação, inicia-se o processo de preparação a tecelagem, em que são feitos os urdumes de fios para a tecelagem: grandes carretéis nos quais os fios são acondicionados de acordo com a estrutura dos produtos a serem produzidos. Após estarem prontos, os urdumes são encaminhados para a área da tecelagem, responsável por transformá-los em tecidos crus. Na sequência, os tecidos crus são direcionados para a área de beneficiamento, a qual irá configurar os tecidos em cores ou estampas. Após o processo de beneficiamento, o tecido segue para a confecção, que irá cortar este tecido e costurar, e também revisar e embalar, podendo o produto ser encaminhado à expedição para ser armazenado/expedido.

\subsection{Aplicação do postponement na empresa pesquisada}

A empresa pesquisada percebeu a necessidade de implantar o postponement na sua estratégia de manufatura após uma série de discussões a respeito da forma como vinha operando. Um grupo composto por gerentes e coordenadores da empresa mapeou alguns processos, conforme a Figura 8, a fim de identificar e iluminar possiveis desperdícios, tornando estes processos mais ágeis, eficientes e eficazes.

Através deste mapeamento, o grupo listou uma série de pontos que necessitavam ser repensados e aprimorados, e esses pontos foram enumerados e colocados em evidência no mapa, de acordo com o processo no qual ocorriam, visando encontrarem-se os centros críticos de atuação, conforme mostrado na Figura 9.

Para que se conseguisse agir de forma priorizada nos pontos principais, todos os itens foram classificados dentro de uma matriz de esforço, conforme apresentada na Figura 10, que leva em consideração os fatores frequência e impacto, classificando-os em alto, médio e baixo.

Após a aplicação dos diversos pontos na matriz de esforço, os principais itens considerados com alta frequência e alto impacto para serem trabalhados foram: maior agilidade na entrega, melhora na programação da produção, melhora nos lead-times de produção e redução nos níveis de estoques.

Estes pontos foram designados para serem analisados e trabalhados pela área de planejamento da empresa,

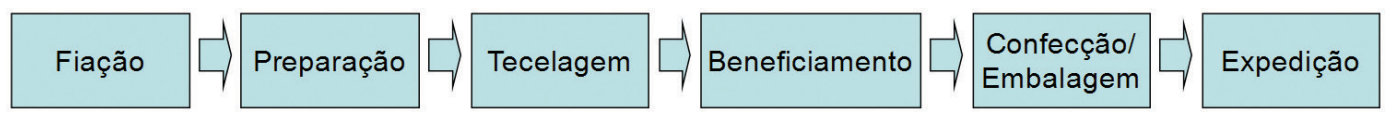

Figura 7. Macrofluxo produtivo da empresa pesquisada. Fonte: Elaborado pelos autores. 
que percebeu que a aplicação do postponement traria impacto em todos os pontos.

A forma de trabalhar adotada pela empresa baseava-se em uma previsão de vendas feita pela área de planejamento, respaldada em inputs da área comercial e de marketing, e que era produzida até o nível de produto acabado, passando por todo o fluxo produtivo apresentado anteriormente. Esta forma de trabalho fazia com que os níveis de estoques acabados aumentassem e muitas vezes se deparasse com a seguinte situação: os clientes faziam pedidos de determinados produtos - e na maioria das vezes bastante consideráveis em termos de volumes e valores -, e os pedidos estavam prontos na expedição, mas

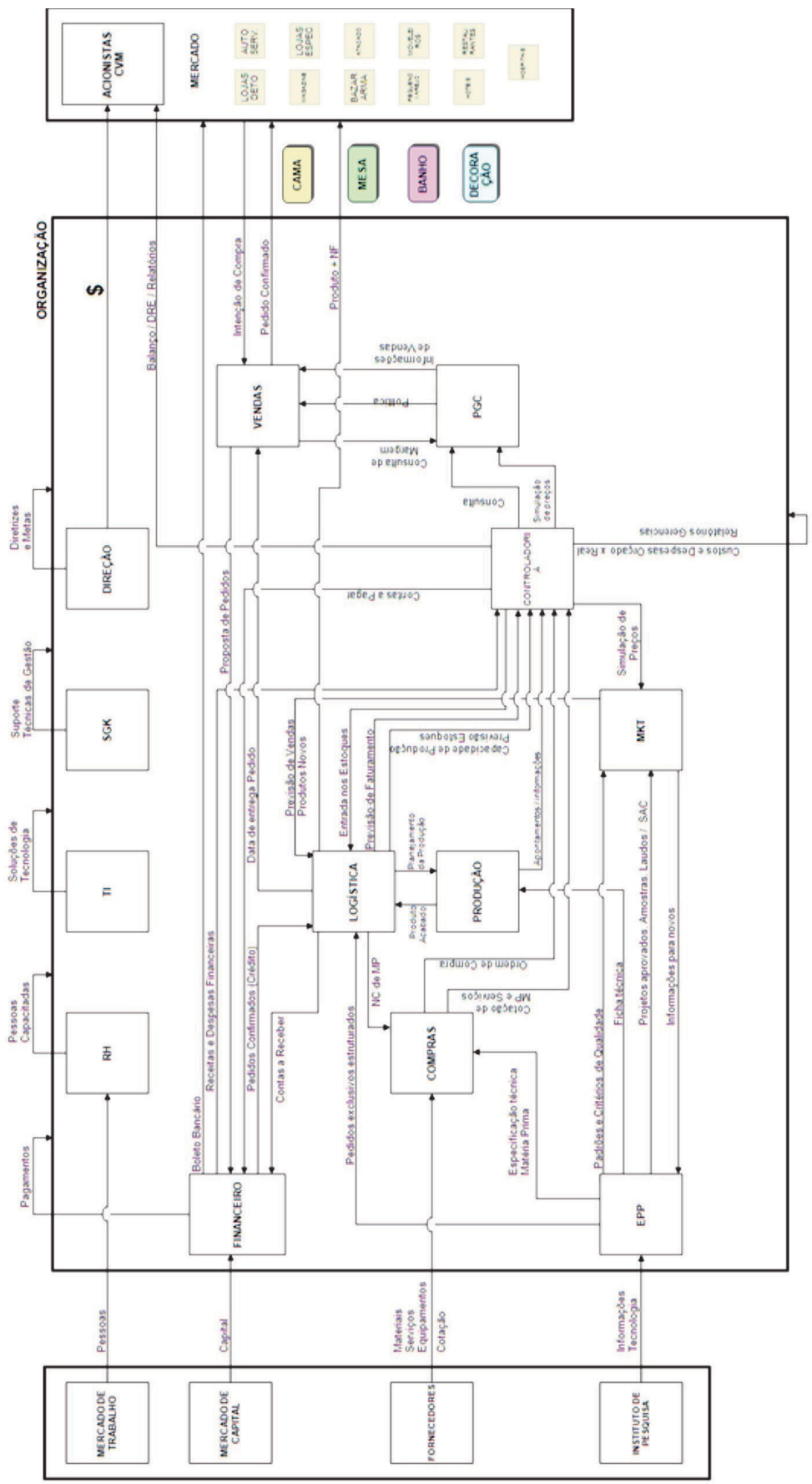

Figura 8. Mapeamento do Fluxo de Valor - Processo de entrada de pedidos da empresa pesquisada. Fonte: Elaborado pelos autores. 


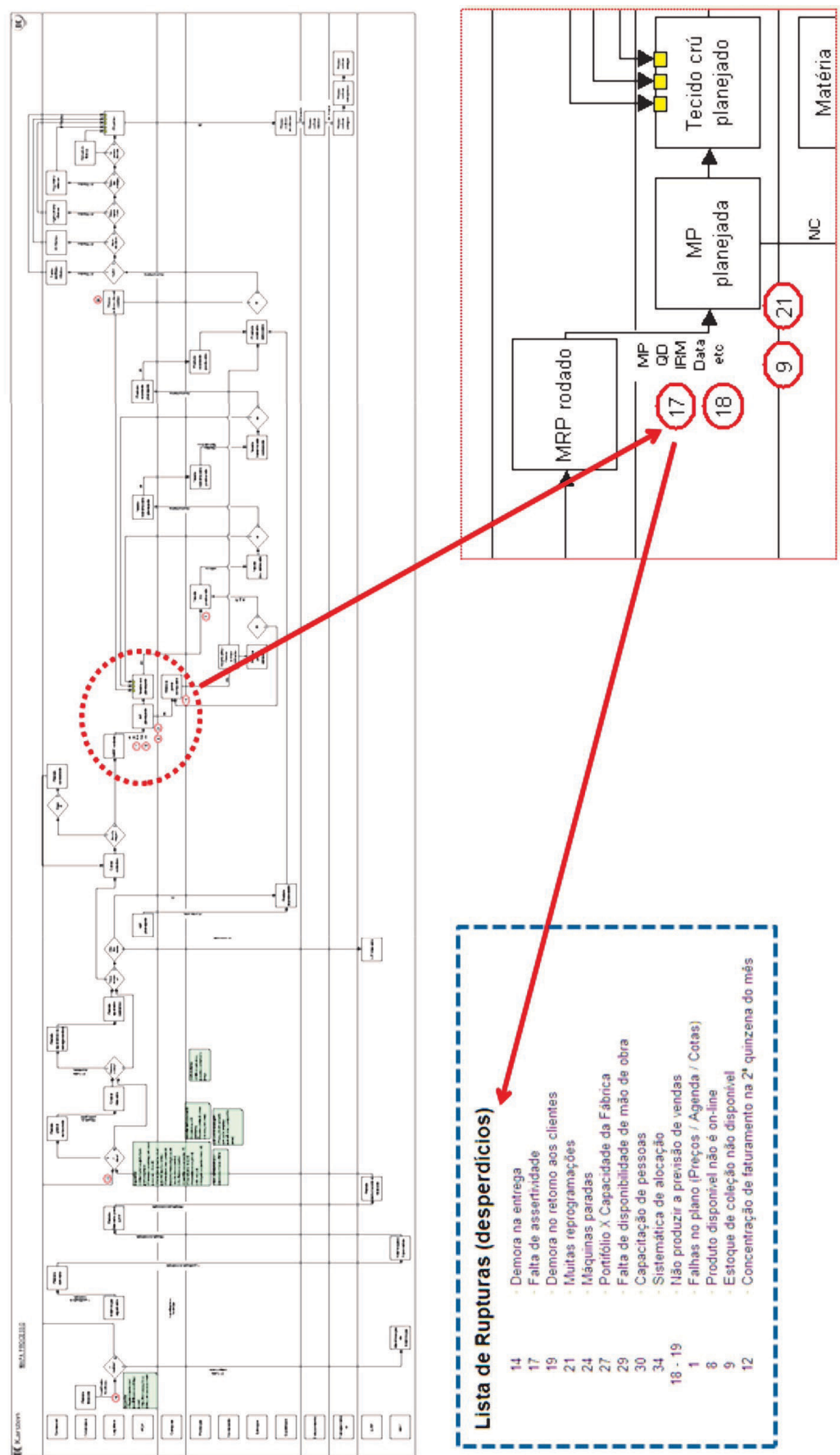

Figura 9. Mapeamento do Fluxo de Valor - Enumeração e detecção dos centros críticos. Fonte: Elaborado pelos autores.

com um problema: estavam configurados em cores diferentes das solicitadas pelos clientes. Isso obrigava a empresa a produzir o produto desde o início da cadeia produtiva, ou seja, teria um longo lead-time (aproximadamente 29 dias, caso fosse desde a tecelagem até a expedição) para deixar o pedido pronto para ser expedido. Outro fator considerado pela empresa em relação aos seus estoques é que tivesse em estoque 15 dias em de tecidos crus disponíveis, e 15 dias de produtos acabados disponíveis, com objetivo de reduzir o lead-time produtivo e, consequentemente, o lead-time de entrega, pois tendo o tecido cru em estoque o lead-time médio de produção considerando de beneficiamento até a expedição é de 10 dias. 


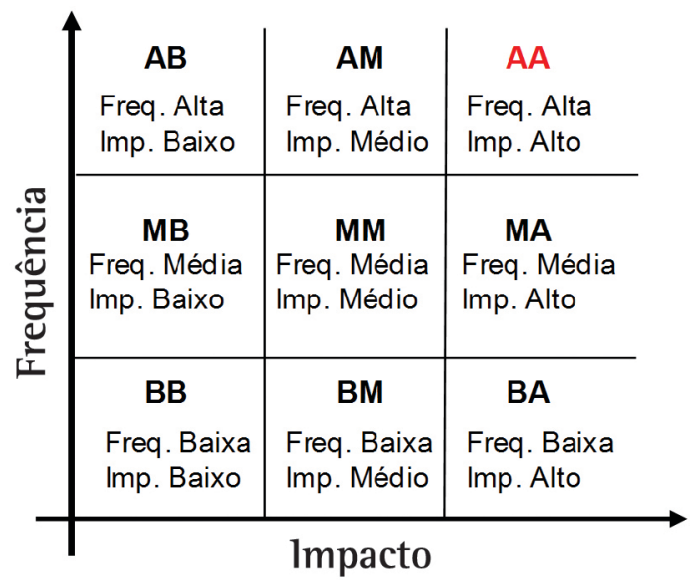

Figura 10. Matriz de esforço. Fonte: Elaborado pelos autores.

Visando à aplicação do postponement, a equipe de planejamento decidiu criar uma matriz para cálculos de previsão de demandas, conforme apresentada na Tabela 3. Esta matriz raciocina de forma ponderada, sempre dando peso maior para o futuro, considerando para a previsão de demandas dos produtos uma visão de 35 dias de carteira futura, ou seja, os pedidos efetivos já confirmados pelos clientes neste horizonte; considera o faturamento ocorrido nos últimos quatro meses anteriores ao mês atual; e também considera os quatro meses futuros em relação ao mês atual, mas com base no ano anterior, para ter uma forma de considerar a sazonalidade e tendência dos períodos. Para os produtos que ainda não existem em algum dos períodos de raciocínio da matriz, os pesos são considerados para os períodos existentes, sempre fechando em 100\%.

Para a aplicação do postponement, a matriz calcula considerando uma nova forma de política de estoques entre os tecidos crus e produtos acabados, alterando a forma anterior que era ter 15 dias de estoques nos tecidos crus e 15 dias de estoques nos produtos acabados, para 25 dias de estoques de tecidos crus e apenas 5 dias de estoques de produtos acabados, conforme Tabela 4.

A empresa pesquisada é praticante do Lean Manufacturing e sabe da importância do combate aos desperdícios, sendo o estoque desnecessário um deles, mas os estoques discutidos neste artigo são de total consciência da empresa, ou seja, não são desnecessários e fazem parte da estratégia desta, o que ajuda na agilidade de produção e entrega.

Como o postponement foi implantado nos tecidos crus e produtos acabados, pode-se dizer que o decoupling point (ponto de desacoplamento) encontra-se entre as áreas de tecelagem, que originam os tecidos crus, e neste nível a produção ocorre de
Tabela 3. Matriz de cálculo de demandas.

\begin{tabular}{cccc}
\hline $\begin{array}{c}4 \text { meses do } \\
\begin{array}{c}\text { Ano Anterior } \\
(\%)\end{array}\end{array}$ & $\begin{array}{c}4 \text { meses } \\
\text { Anteriores (\%) }\end{array}$ & $\begin{array}{c}35 \text { dias } \\
\text { Carteira } \\
(\%)\end{array}$ & $\begin{array}{c}\text { Total } \\
(\%)\end{array}$ \\
\hline 35 & 30 & 35 & 100 \\
50 & - & 50 & 100 \\
100 & - & - & 100 \\
- & 100 & - & 100 \\
70 & 30 & - & 100 \\
- & - & 100 & 100 \\
\hline Fonte: Elaborado pelos autores.
\end{tabular}

Tabela 4. Estratégia de estoques anterior e atual.

\begin{tabular}{ccc}
\hline Forma & $\begin{array}{c}\text { Produto Acabado } \\
\text { (dias) }\end{array}$ & $\begin{array}{c}\text { Tecido Cru } \\
\text { (dias) }\end{array}$ \\
\hline Anterior & 15 & 15 \\
Atual & 5 & 25 \\
\hline Fonte: Elaborado pelos autores. & &
\end{tabular}

acordo com a sinalização da matriz de cálculos de demandas, e da área de beneficiamento, a qual gera a configuração dos produtos através da programação make-to-order (sob pedido), para posteriormente serem produtos acabados.

Após a simulação de previsão de demandas feita com base na matriz de cálculos, e com a nova política de estoques, novos volumes foram projetados, tanto para os tecidos crus quanto para os produtos acabados, conforme mostram as Tabelas 5 e 6.

A Tabela 5 mostra a situação atual e projetada dos estoques de tecidos crus para os dois tipos de produtos, felpudos e lisos, e cada um deles é composto de várias famílias de produção, cada uma com suas caracteristicas particulares. Analisando os volumes totais por tipo, atualmente a empresa possui um estoque de tecidos crus felpudos de 710.806 metros, tendo como projeção de cálculo pela matriz a necessidade de 984.153 metros. Em relação aos tecidos crus lisos, a empresa possui um estoque de 669.693 metros, tendo como projeção de cálculo pela matriz a necessidade de 529.189 metros. Conforme comentado anteriormente, nos tecidos crus a nova política é aumentar os estoques disponíveis de 15 para 25 dias de cobertura. Se notarmos, o tecido felpudo está apresentando um acréscimo de 273.347 metros, e o tecido liso está apresentando uma redução de 140.504 metros, por já estar acima do volume pretendido. No total, entre tecidos felpudos e lisos, o acréscimo de estoques projetado é de 132.843 metros.

A Tabela 6 mostra a situação atual e projetada dos estoques de produtos acabados, também para os dois tipos de produtos, felpudos e lisos, sendo cada um deles também composto de várias famílias de produção, cada uma com suas características particulares. Analisando os volumes totais por tipo, atualmente a empresa possui um estoque de produtos 
Tabela 5. Estoques de tecidos crus por tipo e família - atual e projetado em metros.

\begin{tabular}{|c|c|c|c|}
\hline TIPO & FAMÍLIA & Estoque Atual - Metros & Estoque Projetado - Metros \\
\hline \multirow{9}{*}{ Felpudo } & A & 59.894 & 47.942 \\
\hline & B & 101.137 & 132.995 \\
\hline & C & 41.429 & 9.457 \\
\hline & $\mathrm{D}$ & 139.171 & 168.586 \\
\hline & E & 65.506 & 91.579 \\
\hline & $\mathrm{F}$ & 154.346 & 340.881 \\
\hline & G & 42.912 & 52.197 \\
\hline & $\mathrm{H}$ & 36.761 & 82.294 \\
\hline & 1 & 69.650 & 58.222 \\
\hline \multicolumn{2}{|r|}{ Felpudo Total } & 710.806 & 984.153 \\
\hline \multirow{5}{*}{ Liso } & K & 77.820 & 74.400 \\
\hline & W & 432.442 & 290.410 \\
\hline & $x$ & 103.089 & 95.648 \\
\hline & Y & 50.860 & 57.741 \\
\hline & Z & 5.482 & 10.990 \\
\hline \multicolumn{2}{|r|}{ Liso Total } & 669.693 & 529.189 \\
\hline \multicolumn{2}{|r|}{ Total Geral } & 1.380 .499 & 1.513 .342 \\
\hline
\end{tabular}

Fonte: Elaborado pelos autores.

Tabela 6. Estoques de produtos acabados por tipo e família - atual e projetado em metros.

\begin{tabular}{|c|c|c|c|}
\hline TIPO & FAMÍLIA & Estoque Atual - Metros & Estoque Projetado - Metros \\
\hline \multirow{9}{*}{ Felpudo } & A & 6.052 & 10.193 \\
\hline & B & 167.878 & 73.608 \\
\hline & C & 22.457 & 8.863 \\
\hline & D & 164.437 & 99.479 \\
\hline & E & 154.041 & 80.391 \\
\hline & $\mathrm{F}$ & 384.468 & 179.058 \\
\hline & G & 95.268 & 20.448 \\
\hline & $\mathrm{H}$ & 78.025 & 48.287 \\
\hline & 1 & 110.814 & 62.749 \\
\hline & Felpudo Total & 1.183 .440 & 583.076 \\
\hline \multirow{5}{*}{ Liso } & K & 66.781 & 67.510 \\
\hline & W & 504.812 & 379.177 \\
\hline & $x$ & 87.405 & 115.091 \\
\hline & Y & 53.651 & 51.536 \\
\hline & Z & 8.469 & 2.923 \\
\hline \multicolumn{2}{|r|}{ Liso Total } & 721.118 & 616.237 \\
\hline \multicolumn{2}{|r|}{ Total Geral } & 1.904 .558 & 1.199 .313 \\
\hline
\end{tabular}

Fonte: Elaborado pelos autores.

acabados felpudos de 1.183.440 metros, tendo como projeção de cálculo pela matriz a necessidade de 583.076 metros. Em relação aos produtos acabados lisos, a empresa possui um estoque de 721.118 metros, tendo como projeção de cálculo pela matriz a necessidade de 616.237 metros. Conforme comentado anteriormente, nos produtos acabados a nova política é reduzir os estoques disponíveis de 15 para 5 dias de cobertura. Se notarmos, o produto acabado felpudo está apresentando uma redução de 600.364 metros, e o produto acabado liso está apresentando uma redução de 104.881 metros. No total, entre produtos acabados felpudos e lisos, a redução de estoques projetada é de 705.245 metros.
A seguir serão explanados os impactos desta aplicação nos resultados da empresa pesquisada.

\subsection{Impactos da aplicação do \\ Postponement nos resultados e indicadores de desempenho da empresa pesquisada}

A aplicação do postponement neste caso descrito traz uma série de benefícios para a empresa: redução de volumes de reprocesso de produtos, visto que muitas vezes alguns clientes compram produtos que são da coleção da empresa e que já estão em estoque de produtos acabados, mas querem que seja colocada 
uma etiqueta exclusiva deles, tendo a empresa que, para não gerar mais lotes de produção, retirar os produtos do estoque e reprocessar, alterando as etiquetas atuais pelas solicitadas; redução da venda de estoques obsoletos, o que ocorre em razão de os níveis de produtos acabados diminuírem e a empresa estar operando de forma make-to-order após os estoques de tecidos crus. Isso diminui a chance de sobrar produtos acabados; e com a redução dos estoques de produtos acabados, automaticamente os custos de estocagem também reduzem.

Para esses novos níveis de estoques previstos com os cálculos da matriz, calcularam-se os ganhos e as perdas projetados (custo dos produtos no estoque mais os custos de estocagem), tanto para os tecidos crus quanto para os produtos acabados. Para os tecidos crus, em razão de a estratégia aumentar os volumes de estoques, a empresa terá uma perda de $\mathrm{R} \$ 1.400 .000,00$, mas, em contrapartida, para os estoques de produtos acabados, em que a estratégia é reduzir o volume, a empresa terá um ganho de $\mathrm{R} \$ 7.600 .000,00$, totalizando um ganho de $\mathrm{R} \$ 6.200 .000,00$ relacionado ao custo dos produtos no estoque e os custos de estocagem. Este ganho se dá porque a empresa está mantendo um nível menor de estoque de produtos acabados, pois o custo deste é evidentemente maior do que o custo de estoques de tecidos crus, os quais ainda não passaram pelo processo de beneficiamento ou estamparia e confecção.

Com o postponement, diminuíram-se os erros frequentes de previsão de vendas e, consequentemente, os despachos de produtos errados e desequilíbrios de estoques, visto que se torna cada vez mais difícil fazer uma previsão de vendas para cada variação de produto e ponto de venda.

Muitas áreas de apoio da empresa envolvem-se de forma direta ou indiretamente com a adoção do postponement, como o PCP (Planejamento e Controle da Produção), que precisa ter todas as suas ferramentas de programação, sejam elas desde simples planilhas até sistemas de programação e sequenciamento da produção avançados, configuradas de acordo com as diretrizes definidas para o postponement que a empresa decidiu seguir. As formas de análises, os lead-times de programação, enfim, todas as rotinas de uma área como essa devem estar sintonizadas com a estratégia de postponement. 0 envolvimento profundo da área de controladoria também se faz muito importante, visto que é grande a medição de custos necessária para se avaliar a implementação do postponement para um produto. Devem-se avaliar os custos de postponement em relação aos custos da prática corrente de se alocar produtos para armazéns ou lojas, baseando-se em previsões de vendas. Os custos de manutenção de estoques, transportes, perdas de vendas devido ao longo prazo de entrega e processamento (etiquetagem, embalagem, montagem ou fabricação) devem ser mensurados, para que se possa estimar o custo de distribuição por unidade. As atividades da controladoria e de outras áreas também são impactadas com o postponement, já que os níveis de estoques para inventários são menores, e toda a valorização de estoques e as rotinas de fechamentos contábeis são facilitadas.

Além desses impactos citados, a empresa também teve diversos ganhos em relação a alguns de seus indicadores de desempenho, e os principais indicadores que tiveram impactos foram:

- indicador de OTIF (On time in full): este indicador mede a entrega dos pedidos completos e na data prometida. Após a aplicação do postponement, este indicador na empresa pesquisada chegou a alcançar mais de 92\%;

- indicador de OTD (On time delivery): este indicador mede a entrega dos itens de pedidos na data prometida. Após a aplicação do postponement, este indicador na empresa pesquisada chegou a alcançar mais de 94\%;

- indicador de TTM (Time-to-market): este indicador mede o lead-time da entrega dos pedidos completos. Após a aplicação do postponement, este indicador na empresa pesquisada chegou a alcançar 23 dias.

Todos esses indicadores refletem diretamente no relacionamento da empresa com seus clientes, e os resultados acima descritos, em relação ao setor têxtil, são considerados como referência. E um dos grandes responsáveis é o postponement, o qual faz com que se tenha agilidade e menos desperdícios.

\section{Conclusões}

Constata-se que a estratégia do postponement, se aplicada da forma correta, pode causar grandes impactos no fluxo de caixa das empresas, de modo a não apenas ter consequências e impactos financeiros, mas sim em uma série de fatores que fazem as empresas ganharem agilidade em seus prazos, sejam de produção ou de entrega.

0 postponementé uma estratégia que faz termos a resposta para a pergunta: será que para uma empresa ser lean, ela precisa ser lean em todas as suas áreas? Conclui-se que o postponement ajuda a responder a esta questão, em razão de sua utilização fazer com que tenhamos um estoque conscientemente maior em uma etapa anterior, configurando o mesmo apenas quando o cliente colocar seu pedido efetivo. lsso faz com que se consiga reduzir o lead-time de entrega, bem como o time-to-market, além de diminuir o 
custo do estoque total, pelo fato de os custos de estoques das etapas anteriores serem menores do que do produto já configurado. Também cabe ressaltar que o lean mostra que um de seus desperdícios é o estoque "desnecessário", isto é, como o estoque tem o adjetivo "desnecessário", não necessariamente o lean prega que qualquer estoque seja ruim.

Por meio do postponement, as empresas têm a oportunidade de se diferenciar da concorrência, oferecendo a seus clientes uma gama mais ampla de produtos, enquanto mantêm um investimento baixo em estoques. As empresas também podem evitar custos desnecessários de transporte, negociando melhores taxas de frete no despacho de mercadorias a granel ou de produtos desmontados.

Finalmente, cabe destacar que o postponement pode ser uma importante abordagem para as empresas atenderem os desejos dos clientes de forma personalizada e a menor custo, atingindo assim a customização em massa. Mas a habilidade de a empresa utilizar a abordagem do postponement depende em parte do grau de modularização de seus produtos e processos. E, mais importante: é preciso ter a organização construída de forma consciente e sistemática, com as condições necessárias de estrutura, infraestrutura e um forte relacionamento interorganizacional.

\section{Referências}

Alderson, W. (1950). Marketing efficiency and the principle of postponement. Cost and Profit Outlook, (3), 15-18.

Appelqvist, P., \& Gubi, E. (2005). Postponed variety creation: case study in consumer electronic retail. International Journal of Retail \& Distribution Management, 33(10), 734-748. http://dx.doi.org/10.1108/09590550510622281.

Associação Brasileira da Indústria Têxtil e de Confecção - ABIT. (2011). Apresenta informações sobre o perfil do setor têxtil. São Paulo. Recuperado em 7 de julho de 2011, de http:// www.abit.org.br/site/navegacao.asp?id_menu=1\&id_ sub $=4$ \&idioma $=$ PT

Baldwin, C. Y., \& Clark, K. B. (1997). Managing in an age of modularity. Harvard Business Review, 75(5), 84-93. PMid:10170333.

Barton, D. L. (1990). A dual methodology for case studies: synergistic use of a longitudinal single site with replicate multiple sites. Organization Science, 1(3), 248-266. http:// dx.doi.org/10.1287/orsc.1.3.248.

Bowersox, D. J., \& Closs, D. J. (1996). Logistical management: the integrated supply chain process. New York: McGrawHill Companies. 594 p.

Bucklin, L. P. (1965). Postponement, speculation and the structure of distribution channels. JMR, Journal of Marketing Research, 2(1), 26-31. http://dx.doi.org/10.2307/3149333.

Cardoso, P. A. (2002). O princípio da postergação: um estudo na cadeia de suprimentos das tintas para impressão. (Tese de doutorado). Departamento de Engenharia Industrial,
Pontifícia Universidade Católica do Rio de Janeiro, Rio de Janeiro.

Christopher, M. (1997). Logística e gerenciamento da cadeia de suprimentos: estratégias para redução de custos e melhoria dos serviços. São Paulo: Pioneira. 240 p.

Christopher, M., \& Towill, D. R. (2000). Supply Chain migration from lean and functional to agile and customized. Supply Chain Management, 5(4), 206-213.

Cooper, J. (1993). Logistics strategies for global business. International. Journal of Physical Distribution and Logistics Management, 23(4), 12-23. http://dx.doi. org/10.1108/09600039310041473.

Dornier, P. P., Ernest, R., Fender, M., \& Kouvelis, P. (2000). Logística e operações globais: texto e casos. São Paulo: Atlas.

Ferreira, K. A., Chicarelli, R. L. A., \& Chaves, G. L. D. (2011). Uma caracterização de medidas de desempenho para avaliar o postponement: estudos de caso em empresas da indústria de alimentos. Revista Produção Online, 11(2), 418-446.

Garcia-Dastugue, S., \& Lambert, D. (2007). Interorganizational time-based postponement in the supply chain. Journal of Business Logistics, 28(1), 57-76.

Hoekstra, S. J., \& Romme, J. M. (1992). Integrated logistics structures: developing customer oriented goods flow. London: McGraw-Hill.

Jones, R. M., \& Towill, D. R. (1999). Using the information decoupling point to improve supply chain performance. The International Journal of Logistics Management, 10(2), 13-26.

Lee, H. L. (1998). Postponement for mass customization: satisfying customer demands for tailor-made products. In J. Gattorna (Ed.), Strategic supply chain alignment (pp. 77-91). England: Gower Publishing.

Pagh, J. D., \& Cooper, M.C. (1998). Supply chain postponement and speculation strategies: how to choose the right strategy. Journal of Business Logistics, 19(2), 13-34.

Rudberg, M., \& Wikner, J. (2004). Mass customization in terms of the customer order decoupling point. Production Planning and Control, 15(4), 445-458. http://dx.doi.org/ $10.1080 / 0953728042000238764$.

Starr, M. K. (1965). Modular-production: a new concept. Harvard Business Review, 43(6), 131-142.

Ulrich, K. (1995). The role of product architecture in the manufacturing firm. Research Policy, 24(3), 419-440. http:// dx.doi.org/10.1016/0048-7333(94)00775-3.

Van Hoek, R. 1. (1997). Postponed manufacturing: a case study in the food supply chain. Supply Chain Management, 2(2), 18-34. http://dx.doi.org/10.1108/13598549710166113.

Van Hoek, R. l. (1999). Postponement and the reconfiguration challenge for food supply chains. Supply Chain Management, $4(1), 18-34$

Van Hoek, R. 1. (2001). The rediscovery of postponement a literature review and directions for research. Journal of Operations Management, 19(2), 161-184. http://dx.doi. org/10.1016/S0272-6963(00)00057-7.

Waller, M. A., Dabholkar, P. A., \& Gentry, J. J. (2000). Postponement, product customization, and market-oriented supply chain management. Journal of Business Logistics, 21(2), 133-160.

Yang, B., \& Burns, N. D. (2003). Implications of postponement for the supply chain. International Journal of Production 
Research, 41(9), 2075-2090. http://dx.doi.org/10.1080/0 0207544031000077284.

Yang, B., Burns, N. D., \& Backhouse, C. J. (2004). Postponement: a review and an integrated framework. International Journal of Operations \& Production Management, 24(5), 468-487. http://dx.doi.org/10.1108/01443570410532542.
Zinn, W. (1990). 0 retardamento da montagem final de produtos como estratégia de marketing e distribuição. RAE: Revista de Administração de Empresas, 30(4), 53-59.

Zinn, W., \& Bowersox, D. J. (1988). Planning physical distribution with the principle of postponement. Journal of Business Logistics, 9(2), 117-136.

\section{Practical application of postponement in a textile company \\ Abstract}

Organizations seek increasing numbers of ways to serve their customers in a manner that is faster than that of their competitors while remaining efficient and effective, i.e., by not raising their costs; this constraint requires them to do more with less, seeking the implementation of techniques that can conform to their strategies. In this context, this paper presents the practical application of postponement in a textile company along with an analysis of the results. The work considers a case study, whose evidence was collected from various sources. The results provide an understanding of the manufacturing strategy adopted by the company without and with the adoption of postponement as well as an examination of the impact of application performance indicators of the company used in the study.

\section{Keywords}

Postponement. Decoupling point. Textile company. Performance indicators. Manufacturing strategy. 